\title{
Risky Behaviors and Life Status as Risk Factors for Spontaneous Abortion
}

\author{
Seyed Abbas Hosseini ${ }^{1, *} ;$ Masoumeh Farsi Zaban ${ }^{1}$ \\ ${ }^{1}$ Department of Medicine, Zahedan University of Medical Sciences, Zahedan, IR Iran \\ *Corresponding author: Seyed Abbas Hosseini, Department of Medicine, Zahedan University of Medical Sciences, Zahedan, IR Iran. Tel: +98-9155408625, E-mail: sepehrhssn@yahoo. \\ com
}

Received: January 20, 2014; Revised: May 28, 2014; Accepted: June 16, 2014

\begin{abstract}
Background:The Health outcomes of an individual depend on his /her life position.
Objectives: The purpose of the present paper aimed to study spontaneous abortion (as a high risk factor among rural pregnant) due to their life status.

Patients and Methods: The study was conducted among 40 young rural pregnant women, 12 to 20 years old by implementing a questionnaire during 2012 to 2013 in four villages in southeast of Iran. The women were exposed to high-risk factors such as shortage or lack of drinking water, high pressure electric power sources and chemicals released from burning gas both from cooking and cars as a fuel. The data were collected from the pregnant women coming into clinics. Results of the t-test and chi-square identified significant $(\mathrm{P}<0.05$; $95 \% \mathrm{CI}$ ) and adjustment for birth variables.

Results: The findings revealed that pregnant women were without spontaneous abortion (100\%) in villages of Iranshahr; while the pregnant women in Sarbaz villages experienced spontaneous abortion (30\%). The houses were built from brick (80\%), wood (15\%) and fiber (5\%) in villages of Iranshahr district; and from brick (45\%), and stone (55\%), in villages of Sarbaz district. Twenty percent of residents in the villages of Iranshahr were exposed to high-risk situations, while none in Sarbaz villages. Although all villages had 100\% electric power source, pregnant women had $95 \%$ and 20\% piped drinking water in villages of Iranshahr and Sarbaz, respectively. No houses in both villages were equipped with the gas fuel system.

Conclusions: The findings suggest that a completely programmed surveillance program should be undertaken to implemented remedy in environmental shortages for pregnant rural women.
\end{abstract}

Keywords: Rural Population; Drinking Water; Construction Materials

\section{Background}

Pregnancy is considered as an important period in the women's life. Not only environmental health condition influences the life quality of the mothers, but may also affects the fetus and cause hereditaryy diseases (1). Millions of women do not have access to proper health services in future worldwide. The mains purpose of the rural pregnant women protection program is maintaining health and furnishing during the course of pregnancy by protecting the mother and fetus (2). Studies indicated that spontaneous abortion can be considered as a risk(3). Pregnant women should be aware of their psychological status during pregnancy.

The risk of spontaneous abortion is correlated with mental disorders, that require careful assessment in order to provide women with the necessary information when confronted with pregnancy complications. During pregnancy, women are at a higher risk of being affected by mental disorders due to fetus termination. Spontaneous abortion is more frequent during the coldest months of the year (4). New interventions are made at reducing those factors causing a better environmental quality (5). This can be used in examining spontaneous abortion and related women's health behavior. This method can also be used to evaluate programs and interventions that aim to reduce women spontaneous abortions (6). Mminority of rural pregnant women were to have additional risks. Based on the aforementioned assertions, the present study was conducted to study spontaneous abortion and high-risk behaviors due to life status of rural pregnant womann.

\section{Objectives}

The purpose of the present paper was to study spontaneous abortion as a high-risk factor among the rural pregnant womann due to their life status.

\section{Patients and Methods}

The study favored from 40 rural pregnant women randomly selected from four villages: Sercore and Cohcam in Sarbaz and Karim abad and Badaband in Iranshahr in the province of Baluchestan in Iran. The spontaneous abortion rate was $0 \%$ and $30 \%$ in the villages of Iranshahr and Sarbaz, respectively. Moreover, the researchers implemented a questionnaire to collect the information with regard to individual characteristics, environmental status, building materials, and the abortion rate among rural pregnant women. The required data was collected 
during the women presence at the clinics in the four villages. Note that some of the women who participate in the study readily had an abortion.

In addition to the questionnaire, the participants were also interviewed. Moreover, In order to investigate the association between the risk of abortion in rural pregnant woman and the aforementioned risk factors (lack of fresh drinking water, dangers associated with high pressure electric power sources and chemicals released from burning gas both for cooking and in cars as a fuel, t-test and chi-square were performed. Also, the participant were monitored for possible pregnancy complications towards the end of their pregnancy and at the time of delivery. The purpose of which was to identify possible cases of abortion and any possible correlations with the risk factors.

\section{Results}

Table 1 shows the type of materials constructions used in the building in southeast of Iran and the rate of spontaneous abortion among pregnant rural women in the four villages. Based on the findings, the majority of the village houses of Iranshahr were constructed from brick, (80\%); fiber of plants (15\%); stone (0\%) and wood (5\%). On the other hand, the houses in Sarbaz (without cases of spontaneous abortion) were built by brick (45\%); fiber of plant (0\%), wood (0\%) and stone (55\%).

According to the findings, in the villages of Sarbaz, shortage or lack of piping drinking water, (20\%); the electric power source (100\%); and Gas fuel (0\%) were identified as risk factors playing a part in spontaneous abortion among pregnant women. On the other hand, shortage or lack of piping drinking water (95\%); Electric power (100\%); and Gas fuel (0\%) were among the risk factors for pregnant women in Sarbaz. In addition to the aforementioned risk factors, adjustment of the family to the high risk factors (5\%) was among the factors for the participants. The occurred spontaneous abortion is $0 \%$ and $30 \%$ in villages of Iranshahr and Sarbaz city respectively.

\section{Discussion}

Based on the findings, we realized that a high propor- tion of pregnant women in the villages of Iranshahr were supported by the local health care office. The heath care office provided the women with piped drinking water. In such cases, spontaneous abortion was lowered or hindered during pregnancy. Another factor is legislation which may affect the women's health, by changing or enhancing the socioeconomic status of women and lifestyle to avoid unwanted pregnancies (7).

In addition to above, the materials used in constructing buildings have a significant correlation with the rate of spontaneous abortion (8). The results suggest that the stony and brick houses in a villages of Iranshahr were more than Sarbaz city, result lower spontaneous abortion rate compared to the villages of Sarbaz. A conclusion could be that possible explanation is the association of spontaneous abortion could be caused due to the ambient air. The environmental study indicated that higher dust concentration in the ambient air might affect abortion.

The studies also showed that the indoor smoking was a significant independent factor for the occurrence of abortion. In accord with findings of similar to other studies, the findings of the present study revealed spontaneous abortion as a complex and interrelated with other factors (9). Also, Individuals' physiology conditions are contributed on spontaneous abortion to terminate pregnancy (10). Among women's reasons for terminating pregnancy, health and socioeconomic status related to spontaneous abortion circumstances of pregnant women (11).

This study could also evaluate the life statue of pregnant women. Residents of two rural communities of adults were at risk for low quality due to, carrier of energy, and a variety of social, physical and environmental circumstances. It is evident that factors had poorer health status and lower socioeconomic status (12). Lack of piping drinking water, was $20 \%$ to $95 \%$ among rural pregnant women in the villages of two cities and was more common among users. Piping drinking water restriction increased the risk. The effects of piping drinking water during pregnancy upon fatal and infant survival were assessed. Elevated water element concentrations during pregnancy appears to be protective because of its role in

\begin{tabular}{|c|c|c|c|c|c|}
\hline \multirow[t]{2}{*}{ Location } & \multicolumn{4}{|c|}{ Materials Used in House Construction, \% } & \multirow[t]{2}{*}{ Implemented Spontaneous Abortion } \\
\hline & Brick & Stone & Fiber & Wood & \\
\hline Iranshahr & 80 & 0 & 15 & 5 & 0 \\
\hline Sarbaz & 45 & 55 & 0 & 0 & 30 \\
\hline
\end{tabular}

antioxidant defense for the fetus, particularly in undernourished women (13).

The environmental condition should be explained to the pregnant women by a health staff. This explanation helps them in better management and improvement of their overall health and quality of life. Health care providers should recognize barriers that put these adults at risk for poor drinking water and should be prepared to initiate referrals to community resources. The predicted health outcomes for pregnant women could depend on 
Hosseini SA et al.

the population characteristics, and the drinking water indicator employed (14). Predictions of mortality risk associated with drinking water were not reported. Interpretations of piping drinking water should consider how variation in the physiology and expandability of regional drinking water depots impacts health. National strategies need to be implemented to educate the public about the importance of consuming piping drinking water and other factors based on the recommendations presented in national education campaigns, particularly for the pregnant women (15). Policy makers need to consider spontaneous abortion in pregnant women, so that sound decisions can be made (16).

Despite its implications, every research has some limitations; the present study is not an exception such as answer to some questions. The present study was conducted in two villages, consuming research in other parts of Iran and a different samples may yield different results.

\section{Acknowledgements}

The researchers appreciate the Health Office of Iranshahr and Sarbaz Regions, and Head of Offices Centers.

\section{Authors' Contributions}

The first author design and enforced all the research parts and my colleague took a part in calculated the necessary data and discussing about the questions.

\section{Funding/Support}

This study has been supported by Medical Physics Group.

\section{References}

1. Gravensteen IK, Helgadottir LB, Jacobsen EM, Radestad I, Sandset PM, Ekeberg O. Women's experiences in relation to stillbirth and risk factors for long-term post-traumatic stress symptoms: a retrospective study. BMJ Open. 2013;3(10):e003323.

2. Biggs MA, Gould H, Foster DG. Understanding why women seek abortions in the US. BMC Womens Health. 2013;13:29.

3. Bellieni CV, Buonocore G. Abortion and subsequent mental health: Review of the literature. Psychiatry Clin Neurosci. 2013;67(5):301-10.

4. Cockrill K, Upadhyay UD, Turan J, Greene Foster D. The stigma of having an abortion: development of a scale and characteristics of women experiencing abortion stigma. Perspect Sex Reprod Health. 2013;45(2):79-88.
5. Beydoun MA, Kuczmarski MT, Mason MA, Ling SM, Evans MK, Zonderman $\mathrm{AB}$. Role of depressive symptoms in explaining socioeconomic status disparities in dietary quality and central adiposity among US adults: a structural equation modeling approach. Am J Clin Nutr. 2009;90(4):1084-95.

6. Kuczmarski MF, Cremer Sees A, Hotchkiss L, Cotugna N, Evans MK, Zonderman AB. Higher Healthy Eating Index-2005 scores associated with reduced symptoms of depression in an urban population: findings from the Healthy Aging in Neighborhoods of Diversity Across the Life Span (HANDLS) study. J Am Diet Assoc. 2010;110(3):383-9.

7. Belanger K, Leaderer B, Hellenbrand K, Holford TR, McSharry J, Power ME, et al. Spontaneous abortion and exposure to electric blankets and heated water beds. Epidemiology. 1998;9(1):36-42.

8. Pomerantseva MD, Ramaiia LK, Chekhovich AV. [The genetic monitoring of the house mouse population from areas contaminated by radionuclides as a result of the accident at the Chernobyl Atomic Electric Power Station]. Tsitol Genet. 1996;30(4):42-8.

9. Luchini L, Parazzini F. [Exposure to low-frequency electromagnetic fields and pregnancy outcome: a review of the literature with particular attention to exposure to video terminals]. Ann Ostet Ginecol Med Perinat.1992;113(2):102-13.

10. McCabe-Sellers BJ, Bowman S, Stuff JE, Champagne CM, Simpson PM, Bogle ML. Assessment of the diet quality of US adults in the Lower Mississippi Delta. Am J Clin Nutr. 2007;86(3):697-706.

11. Vitolins MZ, Tooze JA, Golden SL, Arcury TA, Bell RA, Davis C, et al. Older adults in the rural South are not meeting healthful eating guidelines. J Am Diet Assoc. 2007;107(2):265-72.

12. Savoca MR, Arcury TA, Leng X, Bell RA, Chen H, Anderson A, et al The diet quality of rural older adults in the South as measured by healthy eating index-2005 varies by ethnicity. J Am Diet Assoc. 2009;109(12):2063-7.

13. Savoca MR, Arcury TA, Leng X, Chen H, Bell RA, Anderson AM, et al. Association between dietary quality of rural older adults and self-reported food avoidance and food modification due to oral health problems. J Am Geriatr Soc. 2010;58(7):1225-32.

14. Vitolins MZ, Quandt SA, Bell RA, Arcury TA, Case LD. Quality of diets consumed by older rural adults. $J$ Rural Health. 2002;18(1):49-56.

15. Champagne CM, Casey PH, Connell CL, Stuff JE, Gossett JM, Harsha DW, et al. Poverty and food intake in rural America: diet quality is lower in food insecure adults in the Mississippi Delta. JAm Diet Assoc. 2007;107(11):1886-94.

16. Wagener A, Muller U, Brockmann GA. The age of attaining highest body weight correlates with lifespan in a genetically obese mouse model. Nutr Diabetes. 2013;3.e62.

17. Oreopoulos A, Padwal R, Kalantar-Zadeh K, Fonarow GC, Norris $\mathrm{CM}$, McAlister FA. Body mass index and mortality in heart failure: a meta-analysis. Am Heart J. 2008;156(1):13-22.

18. Rahman SM, Akesson A, Kippler M, Grander M, Hamadani JD, Streatfield PK, et al. Elevated manganese concentrations in drinking water may be beneficial for fetal survival. PLoS One. 2013;8(9). e74119.

19. Hafez AS, Fahim HI, Badawy HA. Socioenvironmental predic tors of abortion and stillbirths in an industrial community in Egypt. J Egypt Public Health Assoc. 2001;76(1-2):1-16 